\title{
O MÉTODO BicK DE OBSERVAÇÃo DA RELAÇÃo MÃE-BEBÊ: ASPECTOS CLÍNICOS
}

\author{
Lisiane Machado de Oliveira-Menegotto* \\ Rita de Cássia Sobreira Lopes** \\ Nara Amália Caron ${ }^{* * *}$
}

Resumo

O artigo apresenta o método Bick de observação da relação mãe-bebê como uma ferramenta clínica a partir do relato de uma experiência de aplicação à investigação psicanalítica da relação mãe-bebê com síndrome de Down. Discutimos o potencial terapêutico do método, baseado na função continente do observador. O caso apresentado evidencia a postura empática da observadora que, por meio de uma atitude silenciosa e sutil, oferece um holding para a condição de desamparo vivida pela mãe.

Palavras-chave: método Bick de observação, holding, síndrome de Down.

\section{Abstract}

THE BicK INFANT OBSERVATION METHOD: CLINICAL ASPECTS

The article presents the Bick infant observation method as a clinical tool, based on a research application of the method to the psychoanalytic investigation of the relationship of a mother and her Down syndrome baby. We discuss the therapeutic potential of this method, based on the observer's holding function. The case presented shows the observer's silent, subtle and empathic attitude, which served as holding for the mother's helplessness condition.

Keywords: infant observation, holding, Down syndrome.

* Psicóloga Clínica; Mestre e Doutora em Psicologia do Desenvolvimento do Curso de PósGraduação em Psicologia do Desenvolvimento da Universidade Federal do Rio Grande do Sul (UFRGS).

** Doutora pela University College London (Inglaterra); Pesquisadora do CNPq e Professora do Curso de Pós-Graduação em Psicologia do Desenvolvimento da Universidade Federal do Rio Grande do Sul (UFRGS).

*** Analista didata, Membro efetivo da Sociedade Psicanalítica de Porto Alegre e diretora do Núcleo de Infância e Adolescência; Supervisora do método Bick de observação de bebês. 
O método Bick de observação foi criado, em 1948, pela psicanalista inglesa Esther Bick para acompanhar a relação mãe-bebê. Seu principal objetivo era oportunizar aos estudantes uma experiência prática com bebês, reconhecendo o benefício que esse método de observação pode trazer à formação clínica (Bick, [1964] 2002). Desde a sua criação, o método tem se destacado como um instrumento de aprendizagem, de pesquisa e clínica. Configura-se como uma ferramenta de aprendizagem por permitir acompanhar o desenvolvimento do bebê e a constituição e desdobramento de sua relação com seus familiares, sobretudo com sua mãe. Ainda em relação à aprendizagem, o método Bick de observação ajuda o clínico a desenvolver atitudes que são fundamentais na prática clínica, tais como receptividade, holding, sensibilidade para comunicações infantis, entre outras. Alguns estudos e relatos clínicos têm reconhecido o método Bick de observação como uma poderosa ferramenta para o desenvolvimento pessoal e para a formação clínica de psicoterapeutas e psicanalistas infantis (Briggs, 1999; Caron, Fonseca \& Kompinsky, 2000; Covington, 1991; Davids, Miles, Paton \& Trowell, 1999; Feldman, 2002, 2004; Henry, 1984; King, 2002; Lejderman \& Segal, 2000; Miller, L., 2002; Miller, L, 2002; Mack, 1999; Martini, 2000b; Miles, 2002; Rustin, 2003, 2006; Talberg, 1995; Trowell \& Miles, 1991; Trowell \& Rustin, 1991; Tuters, 1988; Watillon, 1997).

Apesar de o método Bick de observação ter sido criado com o objetivo de auxiliar na formação de psicoterapeutas e psicanalistas de crianças, Bick ([1964] 2002) logo percebeu o seu potencial de gerar novos conceitos sobre o desenvolvimento do bebê e a relação mãe-bebê, podendo configurar-se como um método de investigação psicanalítica. A função primordial da pele no bebê em relaçôes objetais precoces e o desenvolvimento de uma "segunda pele" em situações psicopatológicas foram conceitos criados por Bick ([1968] 2002, [1986] 2002), valendo-se dos relatos através desse método de observação. Portanto, o potencial do método Bick de observação para gerar novos conceitos e contribuir com o avanço da teoria psicanalítica logo foi descoberto por sua própria mentora. Baseados nisso, recentemente, alguns autores têm sugerido aplicar o método à clínica e/ou à investigação psicanalítica, buscando um diálogo do método com a pesquisa científica (Caron, 1995; Covington, 1991; Henry, 1984; King, 2002; Mélega, 1997; Reid, 1997; Reynolds, 2003; Rhode, 2004; Rosa, 1995; Rustin, 1989, 1997, 2006; Shuttleworth, 1995).

O método Bick de observação como uma ferramenta clínica será alvo de discussão no presente artigo, a partir do relato de uma experiência de aplicação à investigação psicanalítica da relação mãe-bebê com síndrome de Down ${ }^{1}$. É principalmente a função continente do observador que confere ao método Bick 
de observação um caráter clínico. Muitos autores vêm chamando a atenção para a função continente da observação (Borensztejn, Abdala, Dimant, Urman \& Ungar, 1998; Caron, 1995; Cresti \& Lapi, 1997; Lejderman \& Kompinsky, 2000; Lisa Miller, 2002; Lynda Miller, 2002; Mélega, 1995, 1997; Rustin, 1997, 2006; Talberg, 1995). O método Bick de observação apresenta implicações clínicas, sobretudo a partir da função continente, desenvolvida no observador.

\section{Os PROCEDIMENTOS DO MÉTODO BICK DE OBSERVAÇÃo}

O método Bick de observação está ancorado nos principais pressupostos da Psicanálise, tais como: inconsciente, transferência e contratransferência e atenção flutuante. Nesse sentido, o observador ocupa lugar de destaque no método. Ele não é neutro, tampouco objetiva manter-se numa atitude de neutralidade, como no caso da observação de cunho experimental. Considerando os aspectos transferenciais, o observador é tido no método Bick de observação como participante, mas sua interferência deve ser a mínima possível, para que não se produzam maiores distorções no que se desenrola na família. Ele deve permanecer no campo emocional do bebê e seu entorno, mas deve evitar causar grandes perturbações no meio familiar. Nas palavras de Caron (1995: 283), o "observador desempenha uma efetiva participação não-verbalizada, não agente, mas vivenciada, ou seja, o observador inclui-se no processo acompanhado".

O método Bick de observação é constituído por três momentos: o momento da observação propriamente dita, o momento do relato da observação e o momento da leitura e discussão do relato da observação, em supervisão coletiva. No que se refere ao primeiro momento, o método Bick de observação, em sua versão original, consiste em observaçōes semanais, com a duração de uma hora cada, durante um período de dois anos (Bick, [1964] 2002; Rustin, 1997, 2003). A regularidade das observações, no mesmo lugar e na mesma hora da semana, demarca um setting constante, permitindo o acompanhamento da relação mãe-bebê (Rustin, 1989, 1997).

Em relação ao segundo momento, todas as observações geram relatos escritos, contendo a descrição narrativa daquilo que foi observado (Rustin, 1997, 2003). O registro da observação deve ser fortuito, casual, mas representativo daquilo que o observador conseguiu editar, consciente ou inconscientemente (Mélega, 1997).

O terceiro momento desse método de observação é o da leitura e discussão do relato em supervisão. A supervisão, baseada em pressupostos da técnica psicanalítica, dirige-se a dois focos: o bebê e seu entorno e o instrumento de observação, que nada mais é do que o observador. A supervisão desempenha um papel fundamental 
no método Bick de observação, uma vez que permite ao observador exercer uma influência benéfica e facilitadora na interação mãe-bebê. Ela opera como contenção das angústias que a observação mobiliza no observador. Por isso, é importante que a supervisão seja conduzida por um Psicanalista clínico e um observador experiente (Mélega, 1995, 1997; Rustin, 2006; Souza, 1995).

\section{Caráter CLÍNico da OBSERVAÇÃo}

Como já foi mencionado anteriormente, o observador ocupa um lugar de destaque no método Bick de observação. Ao mesmo tempo que ele vivencia o impacto emocional, estando na mira de muitas projeções, deve evitar desempenhar papéis a que seja impelido ou dar conselhos ou fazer julgamentos (Bick, [1964] 2002; Rustin, 1997).

Há muitas similaridades desse método observacional com a clínica psicanalítica. Afinal, o método sustenta-se em fundamentos da psicanálise. Tanto no método Bick de observação como na clínica psicanalítica, há uma insistência na confiança e constância do setting. Em ambos os casos, a característica constante faz com que seja possível para o psicanalista e/ou observador identificar variações naquilo que ocorre no setting, permitindo a reflexão sobre as possíveis causas e implicações dessas variações (Rustin, 1997).

Outra aproximação entre o método Bick de observação e a clínica é que o observador, assim como o clínico no âmbito da psicanálise, busca permanecer em compasso de espera, aguardando o desvelar dos significados, mantendo-se numa atitude não especulativa. Freud ([1914] 1987), quando trabalhava na descoberta do inconsciente, mencionou a importância de permanecer num compasso de espera e, seguindo o conselho de seu mestre Charcot, aprendeu que olhando para as mesmas coisas, repetidas vezes, elas começariam a "falar por si mesmas" (Freud, [1914] 1987: 32).

Na observação, os observadores não interpretam ou intervêm clinicamente nas vidas das famílias que são observadas, embora não possamos negar que a simples presença do observador faz uma diferença no setting, podendo ter um efeito terapêutico. Tal potencial terapêutico do método é reconhecido quando a presença do observador, de uma forma sutil e silenciosa, oferece um holding, usando uma expressão de Winnicott ([1971] 1975), ou seja, um ambiente continente, dado por uma postura empática e não intrusiva do observador (Rustin, 2006). O observador não deve interpretar a transferência, diferente da conduta do psicanalista na clínica, até porque suas palavras podem ser tomadas pela 
família como uma desautorização das funções parentais, que estão se construindo na relação com o bebê. Além disso, o contrato realizado com os pais, antes do início das observaçōes, é que o objetivo das observações é aprender sobre a relação mãe-pai-bebê.

A ideia desse método é que o observador aprenda a observar e sentir, antes de refletir teoricamente, além de aprender a tolerar e a apreciar como as mães cuidam de seus bebês e como encontram suas próprias soluçôes. O observador, nesse sentido, deve manter-se numa postura de observador, e o que dá sustentação a isso é o grupo de supervisão (Kompinsky, 2000).

\section{IMPLICAÇÕES CLÍNICAS DO MÉTODO BICK DE OBSERVAÇÃo A PARTIR DE UM ESTUDO DE CASO}

O fato de o observador participar da observação de uma forma vivenciada, empática e não intrusiva faz com que o método tenha um efeito terapêutico. $\mathrm{O}$ valor terapêutico desse método de observação foi mencionado pela própria Esther Bick, que se surpreendeu com a facilidade de encontrar mães que desejavam ter um observador. Frequentemente, essas mães comentavam que se sentiam bem tendo alguém que as acompanhasse regularmente e com quem elas pudessem conversar sobre os seus bebês, sobre o desenvolvimento deles e sobre os seus sentimentos em relação a isso (Bick, [1964] 2002).

O método Bick de observação apresenta implicações clínicas, especialmente quando aplicado em casos e situações atípicas. Observações por meio dele têm sido realizadas no contexto hospitalar, discutindo as implicações clínicas, atingindo não somente os usuários do hospital, mas também a equipe médica e de enfermagem (Bertoldi, 2000; Cresti \& Lapi, 1997; Druon, 1997; Hinshelwood, 2002; Martini, 2000a; Wirth, 2000). As implicações clínicas também têm sido discutidas em estudos em que se apresenta a aplicação do método Bick em crianças institucionalizadas, vítimas de violência doméstica (Appell, 1997; Briggs, 1999; Youell, 2002), e em creches (Jardin, Detry, Denis, Moreau \& Silbermann, 1997; Lejderman \& Kompinsky, 2000).

Outros estudos evidenciam as implicações clínicas do método Bick de observação a partir de observaçōes no contexto de ultrassonografia (Caron et al., 2000), no contexto de diagnóstico ecográfico de malformação (Caron \& Maltz, 1994) e de diagnóstico perinatal de malformação congênita (Rajon, Rosé \& Abadie, 1997). Essas implicações ficaram ainda mais evidentes em casos em que o método foi 
aplicado no tratamento de desordens funcionais severas da primeira infância, tais como psicose infantil (Houzel, 1997, 1999) e autismo (Reid, 1997).

O caso estudado, que será alvo de discussão no presente artigo, refere-se a uma aplicação do método Bick de observação a partir da observação de um bebê com síndrome de Down e seus pais, sobretudo a sua mãe. As observações ocorreram semanalmente, na residência do bebê, ao longo do primeiro ano de vida dele. Ao todo foram 51 observações, relatadas e discutidas em supervisão coletiva. Foram realizadas pela primeira autora e a supervisão foi conduzida pela segunda autora deste artigo.

Poliana e João ${ }^{2}$ foram surpreendidos no $4^{\circ}$ mês gestacional com a notícia de que o primeiro filho nasceria com síndrome de Down. O diagnóstico foi revelado através de amniocentese, que fora indicada depois de detectada uma probabilidade estatística relativamente alta para malformaçōes e alterações genéticas, tal como a síndrome de Down (1:168), no exame da transluscência nucal. Os pais, na época com 28 anos, estavam casados há dois anos e haviam planejado a gravidez. Ficaram estarrecidos com a notícia, pois era algo que eles jamais esperavam ocorrer.

A observadora foi apresentada aos pais de Gabriel na 20a semana gestacional por intermédio da presidente de uma instituição voltada ao apoio de pessoas com síndrome de Down e seus familiares. O primeiro contato com a família foi realizado através de um telefonema, quando a observadora se apresentou e convidou-os a participar da pesquisa. A mãe, prontamente, aceitou participar, antes mesmo de a observadora explicar com mais detalhes sobre os procedimentos das observações, o que apoia a ideia de Bick ([1964] 2002) de que, em geral, as mães sentem-se bem podendo contar com alguém que as acompanhe sistematicamente. Nesse primeiro contato telefônico, Poliana descreveu em detalhes a sequência de fatos que resultou no diagnóstico de síndrome de Down. Ela parecia estar ainda muito tomada pela dor e pelo sofrimento decorrentes da notícia de que eles teriam um filho com síndrome de Down, frustrando todas as expectativas e desejos construídos em relação ao filho. Muitos relatos clínicos e de pesquisa têm evidenciado o impacto do diagnóstico de síndrome de Down nos pais, especialmente nas mães (Atkinson et al., 1995; Barnett \& Boyce, 1995; Coriat, 1997; Dumas, Wolf, Fisman \& Culligan, 1991; Hastings, Thomas \& Delwiche, 2002; Hodapp, Ricci, Ly \& Fidler, 2003; Jerusalinsky, 1989; Jerusalinsky, 2002; Jerusalinsky \& Coriat, 1983; Jiménez, 2000; Mannoni, [1964] 1995; Oliveira, 2001; Padeliadu, 1998; Pelchat et al., 1999; Pelchat, Bisson, Bois \& Saucier, 2003; Pérez de Plá, 2000; Ricci \& Hodapp, 2003; Rodrigue, Morgan \& Geffken, 1990; Schmidt, 1996; Skotko, 2005; Smith, Innocenti, Boyce \& Smith, 1993; Stores, Stores, Fellows \& Buckley, 1998; Tanaka \& Niwa, 1991, 1994). 
Tanto nesse primeiro contato como nos demais durante a gestação, a observadora relatou que sentia que Poliana parecia precisar falar e ser escutada. Era como se pedisse um testemunho para seu sofrimento por meio de alguém que reconhecesse que aquilo que ela estava passando era realmente algo muito doloroso e assustador. Poliana questionava-se: "nós tínhamos que ser o 1 do 168?", demonstrando estar inconformada com o diagnóstico de síndrome de Down.

A observadora e Poliana agendaram um encontro para se conhecerem e combinarem sobre as observações após o nascimento do bebê. Essa visita ocorreu quando a mãe estava na $22^{\mathrm{a}}$ semana gestacional e a observadora novamente teve a sensação de que ela precisava falar como uma forma de buscar alívio para a sua dor. Ao chegar em frente à casa, a observadora deparou-se com uma construção ainda inacabada, no mesmo terreno da casa dos pais de Poliana, mais precisamente em cima da garagem da casa deles. $\mathrm{O}$ acesso à casa se dava por uma escada que não possuía corrimão e nem parapeito no topo, logo em frente à porta. Assim que Poliana recebeu a observadora no portão, perguntou se ela teria medo de subir as escadas sem corrimão. Tal questionamento de Poliana gerou reflexões acerca das implicações clínicas do método Bick de observação. Estaria Poliana testando a observadora no sentido de ver se ela suportaria a sua dor? Poliana não estaria manifestando o seu temor de não poder contar com ninguém para suportar a sua dor? Poliana parecia estar perguntando para a observadora se ela poderia amparála, sendo o seu "corrimão".

Os pais de Gabriel receberam a observadora de uma forma muito amistosa e informal. Falaram sobre a história do casal, mostraram fotos do casamento, apresentaram a sua família através das fotos e também falaram sobre o bebê e, novamente, sobre o diagnóstico de síndrome de Down. Também mencionaram que estavam tristes com a repercussão da notícia na família e na cidade onde moram, pois todos insistiam em falar sobre o ocorrido com eles, fazendo-os, possivelmente, se sentir julgados, invadidos, criticados e excluídos. A observadora despediu-se dos pais sentindo-se pesada, o que a fazia imaginar que as observações seriam muito intensas e difíceis. Afinal, ela estava contatando a dor, especialmente da mãe, que era manifestada explicitamente. Além disso, nesses dois primeiros contatos, a observadora foi tomada por um intenso sentimento de intervir com palavras de consolo e com informaçôes positivas sobre a síndrome.

O bebê, chamado de Gabriel, nasceu de cesariana na 36a semana gestacional, mas não precisou ser internado em UTI Neonatal por não apresentar nenhuma complicação, além da síndrome de Down. A observadora foi visitá-los no hospital no dia seguinte ao parto. Deparou-se com Poliana em trajes íntimos, uma situação um tanto constrangedora para ambas. Poliana ficou envergonhada e a observadora 
não sabia se entrava ou permanecia na antessala. Esse episódio foi posteriormente compreendido pelo grupo de supervisão como um prenúncio de uma defesa constituída por Poliana para lidar com seu próprio desamparo. Após o nascimento de Gabriel, Poliana passou a esconder a sua intimidade, impedindo manifestações explícitas de dor e sofrimento.

Ao contrário daquilo que a observadora havia previsto, as observações, que iniciaram quando Gabriel estava com 22 dias, passaram a ser sentidas como agradáveis e leves, com exceção dos episódios em que a mãe de Poliana estava presente. Isso porque a mãe dela estava com câncer em estado terminal e todas as observaçôes em que ela estava presente eram extremamente pesadas. Poliana e Gabriel, no entanto, pareciam estar alheios a todo e qualquer sofrimento. A observadora relatou situações em que a mãe de Poliana estava gemendo de dor em um quarto ao lado da sala em que estavam, e Poliana parecia não se afetar, enquanto Gabriel permanecia dormindo. Essas observações eram relatadas como extremamente angustiantes, pois de um lado a observadora testemunhava uma situação de morte iminente e, de outro, uma certa dissociação de Poliana. Quando ela falava da doença de sua mãe, a observadora tinha a sensação de que Poliana não estava falando de uma doença grave e tampouco de sua própria mãe. Parecia estar afastada de todo esse impacto emocional. A notícia da morte da mãe de Poliana chegou na $10^{\mathrm{a}}$ observação e, novamente, Poliana mostrou-se inabalável, cuidando para não demonstrar afeto. Disse que todos deveriam se distrair, para não se lembrar da mãe.

A observadora costumava relatar o seu estranhamento diante das reaçóes de Poliana. Na realidade, a estranheza era em relação ao funcionamento de Poliana em decorrência da defesa construída por ela mesma para não se defrontar com a dor. Durante a gestação, Poliana conseguia manifestar explicitamente a sua vulnerabilidade, mas após o nascimento de Gabriel criou um sistema defensivo para impedir a dor provocada pelas perdas: a perda de sua mãe e de todos os ideais construídos para o filho. Não foi ao acaso a escolha do codinome Poliana. Ele faz uma alusão à protagonista de um dos maiores clássicos da literatura infanto-juvenil: Pollyanna (Porter, [1912] 1978) que, mesmo diante das piores situações, sempre via o lado bom das coisas. Esse foi o funcionamento adotado por Poliana após o nascimento de Gabriel e que se intensificou com a morte de sua mãe.

Poliana constitui uma relação com o bebê a partir de um ritual pré-programado, organizando as observações num mesmo início, meio e fim. Enquanto as observações estavam ocorrendo, a observadora relatava que eram agradáveis. Foi somente quando terminaram, no momento em que os relatos de observação foram lidos, que a observadora percebeu o quanto o ritual e o comportamento estereotipado de Poliana fizeram com que fossem enfadonhas. É possível que o fato de 
a observadora somente perceber as observações como enfadonhas após o término das mesmas tenha sido fundamental para a sua continuidade. Na realidade, as observaçōes eram extremamente pesadas, mas encobertas por uma defesa que fazia parecer que estava tudo bem. Durante as observações, a observadora pôde somente contatar a defesa, aquilo que poderia aparecer, mas após o término das mesmas a observadora conseguiu contatar aquilo que estava em estado latente.

Uma pessoa que ocupou um lugar de destaque em muitas dessas observações foi Maria, irmã mais velha de João. Ela fez, de certa forma, uma espécie de suplência da mãe de Poliana, ajudando-a a cuidar da casa e de Gabriel de uma forma muito afetuosa e delicada. Diante de sua presença, a observadora sempre relatava sentimentos de tranquilidade. Parecia aliviada por ver que a mãe poderia contar com alguém tão amorosa. Lendo os relatos de observação após o término das mesmas, a observadora percebeu que, na presença de Maria, ela se sentia mais leve, como se todo o peso absorvido pela observadora, já que ele não podia ser sentido pela mãe, fosse compartilhado com Maria, deixando a observadora, pelo menos em parte, aliviada.

Uma das funções fundamentais da observadora foi carregar o sofrimento da mãe. Embora ao longo das observações o peso não tenha sido sentido pela observadora, o que garantiu a sua continuidade, após o término delas ela percebeu o quão pesados e enfadonhos eram os encontros e o quanto a presença de Maria era importante para ajudá-la a conter a angústia. A condição empática da observadora garantiu que Poliana não sofresse interferências, críticas e julgamentos, tal como ela mencionava sentir perante as pessoas com as quais convivia na pequena cidade onde moravam. Poliana parecia querer pedir uma trégua para tudo isso. Um lugar do qual a síndrome de Down e as perdas não fizessem parte. Um lugar onde ela pudesse se refazer de todo o sofrimento sem ter que corresponder a algum ideal social. Isso só foi possível porque a observadora manteve-se numa postura empática, de receptividade (Borensztejn et al., 1998; Houzel, 1997, 1999; Lynda Miller, 2002).

Numa das observaçôes, Poliana relata um episódio em que está numa loja e uma pessoa faz um comentário sobre os olhos puxados do filho. Poliana não comentou nada sobre a síndrome de Down, dizia estar cansada de dar explicações sobre isso:

Poliana ainda comentou que Gabriel dormiu em seu colo e que a atendente da loja comentou que os olhos dele pareciam de "japonesinho". Ela refere que resolveu nem comentar nada a respeito da síndrome de Down, ficou em silêncio. Diz que quando ele está de olhos fechados a síndrome de Down fica 
mais saliente, ao passo que, de olhos abertos, fica difícil de ver a síndrome $\left(8^{\mathrm{a}}\right.$ observação, 2 meses e 8 dias).

A receptividade, a partir da função continente do observador, neste caso foi fundamental para que a mãe pudesse encontrar nas observações um espaço onde ela pudesse construir a sua relação com o filho. Pouco a pouco, Poliana foi estabelecendo uma relação de confiança com a observadora, permitindo o afrouxamento de sua defesa em alguns momentos, embora tenham sido extremamente fugazes. Passou a relatar para a observadora situaçôes que escondia do pediatra e das outras pessoas, tais como alguns pequenos acidentes ou fatos em que não seguia as suas recomendações.

Desde que Gabriel nasceu, a mãe levava-o para a Estimulação Precoce, realizada por uma psicomotricista. A observadora relatava as evoluçôes no desenvolvimento neuropsicomotor de Gabriel, mas muitas vezes questionava-se se Poliana estaria tendo um espaço de acolhida e escuta na intervenção, na medida em que parecia haver um certo descompasso entre a mãe e o bebê. Poliana adiantava-se oferecendo o seio antes mesmo de Gabriel solicitá-lo. Gabriel, por sua vez, mostrava-se apagado, raramente chorava e demonstrava incômodos. O relato da observação era de um bebê muito passivo e apático e de uma mãe que não dava espaço para ele se manifestar.

O que incrementava ainda mais a preocupação da observadora era que percebia que a família de Poliana a havia encarregado de cuidar dela, assim como Maria e eventualmente o pai de Poliana cumpriam com essa função. Todos pareciam carregar o sofrimento de Poliana. O pai dela era descrito por ela como alguém atrapalhado, e talvez ele fosse o único que estivesse se permitindo se atrapalhar diante da dor que carregava. Maria ficou nos primeiros meses com Poliana, ajudando-a com os cuidados de Gabriel e com a casa. O pai de Poliana acompanhava-a sempre que era preciso. Costumava pegá-la no trabalho e trazê-la para casa com Gabriel no final do dia. Quando a observadora chegava, o pai de Poliana deixava-a a sós com a observadora e com o bebê e aproveitava para sair e, como ela comentava, "dar as suas voltas".

O estudo evidenciou a importância de alguém que acompanhasse a mãe e pudesse fazer um holding de seu sofrimento. Afinal, o diagnóstico de síndrome de Down e a morte de sua mãe haviam acionado em Poliana sentimentos de dor e desamparo. Poderíamos reconhecer essa atitude continente da observadora como uma intervenção silenciosa e, portanto, sutil. Essa experiência também evidenciou a importância de o terapeuta de Estimulação Precoce incorporar essa atitude continente, acolhendo e amparando a mãe nesse momento de eclosão de dor e sofrimento. 


\section{CONSIDERAÇŌES FINAIS}

O método Bick de observação tem implicações clínicas em função de seu caráter terapêutico. A presença de um observador empático e delicado, que possa oferecer um olhar continente, pode ser considerada, no presente caso, uma intervenção silenciosa e sutil que pode ser incorporada por profissionais que se ocupam do atendimento do bebê e seus familiares nesse período.

A observação do bebê Gabriel e de seus familiares, principalmente de sua mãe, apontou para a importância de poder contar com um amparo psicológico desde o momento em que o diagnóstico é revelado. Afinal, o diagnóstico de síndrome de Down tem repercussões no psiquismo da mãe, podendo gerar um afastamento entre a mãe e o bebê. A presença de um observador que incorpore uma atitude continente é fundamental para resgatar a mãe de seu desamparo, desde que respeite as defesas constituídas por ela, mantendo-se na função observante, sem interferências. Assim, a mãe sente-se apoiada e autorizada a constituir-se como mãe a partir da relação com o seu bebê.

\section{REFERÊNCIAS}

Appell, G. (1997). Que tipo de observação usar para acompanhar uma criança pequena em coletividade. In: Lacroix, M. B. \& Monmayrant, M. (eds.). Os laços do encantamento: a observação de bebês, segundo Esther Bick, e suas aplicações (pp. 79-85). Porto Alegre: Artes Médicas.

Atkinson, L., Scott, B., Chisholm, V., Blackwell, J., Dickens, S., Tam, F. \& Goldberg, S. (1995). Cognitive coping, affective distress, and maternal sensitivity: mothers of children with Down Syndrome. Developmental Psychology, 31, 668-676.

Barnett, W. S. \& Boyce, G. C. (1995). Effects of children with Down Syndrome on parents' activities. American Journal on Mental Retardation, 100, 115-127.

Bertoldi, S. G. (2000). No limite da vida e da morte: aplicação da ORMB no ensino médico. In: Caron, N. A. (ed.). A relação pais-bebê: da observação à clínica (pp. 249-267). São Paulo: Casa do Psicólogo.

Bick, E. (1964/2002). Notes on infant observation in psycho-analytic training. In: Briggs, A. \& Meltzer, D. (eds.). Surviving space: papers on infant observation (pp. 37-54). London: Karnac Books.

Bick, E. (1968/2002). The experience of the skin in early object relations. In: Briggs, A. \& Meltzer, D. (eds.). Surviving space: papers on infant observation (pp. 55-59). London: Karnac Books. 
Bick, E. (1986/2002). Further considerations on the function of the skin in early object relations. In: Briggs, A. \& Meltzer, D. (eds.). Surviving space: papers on infant observation (pp. 60-71). London: Karnac Books.

Borensztejn, C. L., Abdala, N. G. K., Dimant, S. N., Urman, C. N. \& Ungar, V. (1998). Infant observation and its relation to our work as psychoanalysts. The International Journal of Infant Observation, 1(2), 71-83.

Briggs, S. (1999). Links between infant observation and reflexive social work practice. Journal of Social Work Practice, 13, 147-156.

Caron, N. A. (1995). Fundamentos teóricos para a aplicação do método de E. Bick. Revista Brasileira de Psicanálise, 29(2), 283-291.

Caron, N. A. \& Maltz, R. S. (1994). Intervenção em gestantes com anomalias fetais. Revista de Psiquiatria da Sociedade de Psiquiatria do Rio Grande do Sul, 16, 202-207.

Caron, N. A., Fonseca, M. M. C. \& Kompinsky, E. (2000). Aplicação da observação na ultra-sonografia obstétrica. In: Caron, N. A. (ed.). A relação pais-bebê: da observação à clínica (pp. 178-206). São Paulo: Casa do Psicólogo.

Coriat, E. (1997). Psicanálise e clínica de bebês. Porto Alegre: Artes e Ofícios.

Covington, C. (1991). Infant observation re-viewed. Journal of Analytical Psychology, 36, 63-76.

Cresti, L. \& Lapi, I. (1997). O esboço da relação mãe-bebê e a instituição hospitalar: díade ou tríade. In: Lacroix, M. B. \& Monmayrant, M. (eds.). Os laços do encantamento: a observação de bebês, segundo Esther Bick, e suas aplicações (pp. 149-162). Porto Alegre: Artes Médicas.

Davids, Z., Miles, G., Paton, A. \& Trowell, J. (1999). Issues for seminar leaders in infant and young child observation: a comparative study. The International Journal of Infant Observation, 2(3), 16-29.

Druon, C. (1997). Como o espírito vem ao corpo das crianças em UTI Neonatal. In: Lacroix, M. B. \& Monmayrant, M. (eds.). Os laços do encantamento: a observação de bebês, segundo Esther Bick, e suas aplicações (pp. 139-148). Porto Alegre: Artes Médicas.

Dumas, J. E., Wolf, L. C., Fisman, S. N. \& Culligan, A. (1991). Parenting stress, child behavior problems, and dysphoria in parents of children with autism, Down syndrome, behavior disorders, and normal development. Exceptionality, 2, 97-110.

Feldman, B. (2002). The lost steps in infancy: symbolization, analytic process and the growth of the self. Journal of Analytical Psychology, 47, 397-406.

Feldman, B. (2004). A skin for the imaginal. Journal of Analytical Psychology, 49, 285311.

Freud, S. (1914/1987). História do movimento psicanalítico. Obras completas, ESB, v. XIV. Rio de Janeiro: Imago. 
Hastings, R. P., Thomas, H. \& Delwiche, N. (2002). Grandparent support for families of children with Down's syndrome. Journal of Applied Research in Intellectual Disabilities, 15, 97-104.

Henry, G. (1984). Reflections on infant observation and its applications. Journal of Analytical Psychology, 29, 155-169.

Hinshelwood, R. D. (2002). Applying the observational method: observing organizations. In: Briggs, A. \& Meltzer, D. (eds.). Surviving space: papers on infant observation (pp. 157-171). London: Karnac Books.

Hodapp, R. M., Ricci, L. A., Ly, T. M. \& Fidler, D. J. (2003). The effects of the child with Down syndrome on maternal stress. British Journal of Developmental Psychology Society, 21, 137-151.

Houzel, D. (1997). Uma aplicação terapêutica da observação dos lactentes. In: Lacroix, M. B. \& Monmayrant, M. (eds.). Os laços do encantamento: a observação de bebês, segundo Esther Bick, e suas aplicaçôes (pp. 193-207). Porto Alegre: Artes Médicas.

Houzel, D. (1999). A therapeutic application of infant observation in child psychiatry. The International Journal of Infant Observation, 2(3), 42-53.

Jardin, F., Detry, L., Denis, P., Moreau, A. \& Silbermann, A. (1997). A observação do bebê na creche. In: Lacroix, M. B. \& Monmayrant, M. (eds.). Os laços do encantamento: a observação de bebês, segundo Esther Bick, e suas aplicaçôes (pp. 163-173). Porto Alegre: Artes Médicas.

Jerusalinsky, A. N. (1989). A direção da cura do que não se cura. In: Jerusalinsky, A. N. (ed.). Psicanálise e desenvolvimento infantil (pp. 56-71). Porto Alegre: Artes Médicas.

Jerusalinsky, A. N. \& Coriat, E. (1983). Função materna e estimulação precoce - experiência controlada com 100 sujeitos de 3 a 16 meses de idade cronológica. Escritos da Criança, 1, 76-85.

Jerusalinsky, J. (2002). Enquanto o futuro não vem: a psicanálise na clinica interdisciplinar com bebês. Salvador: Ágalma.

Jiménez, A. F. (2000). El niño con síndrome de Down y sus padres. In: Pérez de Plá, E. \& Hernández, S. C. (eds.). Sujeto, inclusión y diferencia: investigación psicoanalítica y psicosocial sobre el sindrome de Down y otros problemas del desarrollo (pp. 141-156). Ciudad de México: Universidad Autónoma Metropolitana, Unidad Xochimilco.

King, R. (2002). Experience of undertaking infant observation as part of the Post-Qualifying Award in Child Care. Journal of Social Work Practice, 16, 213-222.

Kompinsky, E. (2000). Observação de bebês: método e sentimentos do observador. In: Caron, N. A. (ed.). A relação pais-bebê: da observação à clínica (pp. 9-43). São Paulo: Casa do Psicólogo. 
Lejderman, A. T. \& Kompinsky, E. (2000). Caráter preventivo da aplicação da observação da relação mãe-bebê em uma creche. In: Caron, N. A. (ed.). A relação pais-bebê: da observação à clínica (pp. 268-290). São Paulo: Casa do Psicólogo.

Lejderman, A. T. \& Segal, J. (2000). Repercussões da observação da relação mãe-bebê na prática clínica do psicoterapeuta. In: Caron, N. A. (ed.). A relação pais-bebê: da observação à clínica (pp. 329-336). São Paulo: Casa do Psicólogo.

Mack, B. (1999). The contribution of infant observation to therapeutic social work with a child in need. The International Journal of Infant Observation, 2(2), 102-115.

Mannoni, M. (1964/1995). A criança retardada e a mãe. São Paulo: Martins Fontes.

Martini, I. I. (2000a). Em uma enfermaria de cardiologia pediátrica. In: Caron, N. A. (ed.). A relação pais-bebê: da observação à clínica (pp. 233-248). São Paulo: Casa do Psicólogo.

Martini, I. I. (2000b). Modificações que a ormb promove no analista. In: Caron, N. A. (ed.). A relação pais-bebê: da observação à clinica (pp. 337-347). São Paulo: Casa do Psicólogo.

Mélega, M. P. (1995). A supervisão da observação da relação mãe-bebê: ensino e investigação. Revista Brasileira de Psicanálise, 29(2), 263-282.

Mélega, M. P. (1997). Pesquisa da atividade simbólica com ênfase no estudo do brincar: método de observação mãe-bebê Esther Bick. Revista Brasileira de Psicanálise, 31(3), 745-760.

Miles, G. (2002). The experience of teaching and learning in social work. The teaching of young child observation: a historical overview. Journal of Social Work Practice, 16(2), 207-211.

Miller, Lisa (2002). Lessons from infant observation: the developing mind of the infant. The International Journal of Infant Observation, 5(1), 21-35.

Miller, Lynda (2002). The relevance of observation skills to the work discussion seminar. The International Journal of Infant Observation, 5(1), 55-73.

Oliveira, L. M. (2001). O desejo parental diante do impacto do diagnóstico de sindrome de Down. Dissertação de Mestrado, Programa de Pós-graduação em Psicologia do Desenvolvimento, Instituto de Psicologia, Universidade Federal do Rio Grande do Sul. Porto Alegre, Brasil.

Padeliadu, S. (1998). Time demands and experienced stress in Greek mothers of children with Down's syndrome. Journal of Intellectual Disability Research, 42(2), 144-153.

Pelchat, D., Ricard, N., Bouchard, J.-M., Perreault, M., Saucier, J.-F., Berthiaume, M. \& Bisson, J. (1999). Adaptations of parents in relation to their 6-months-old infant's type of disability. Child: Care, Health and Development, 25(4), 377-397. 
Pelchat, D., Bisson, J., Bois, C. \& Saucier, J. (2003). The effects of early relational antecedents and other factors on the parental sensitivity of mothers and fathers. Infant and Child Development, 12, 27-51.

Pérez de Plá, E. (2000). El sujeto, el cuerpo y el otro: la constitución subjetiva de los niños con problemas del desarrollo, con especial énfasis en el síndrome de Down. In: Pérez de Plá, E. \& Hernández, S.C. (eds.). Sujeto, inclusión y diferencia: investigación psicoanalítica y psicosocial sobre el sindrome de Down y otros problemas del desarrollo (pp. 23-95). Ciudad de México: Universidad Autónoma Metropolitana, Unidad Xochimilco.

Porter, E. H. (1912/1978). Pollyanna. São Paulo: Compañía Editora Nacional.

Rajon, A., Rosé, D. \& Abadie, I. (1997). Observação do lactente e atendimento terapêutico do par mãe-filho, no contexto do diagnóstico perinatal de malformação. In: Lacroix, M. B. \& Monmayrant, M. (eds.). Os laços do encantamento: a observação de bebês, segundo Esther Bick, e suas aplicaçôes (pp. 225-231). Porto Alegre: Artes Médicas.

Reid, S. (1997). The development of autistic defenses in an infant: the use of a single case study for research. Infant Observation: The International Journal of Infant Observation and its Application, 1(1), 51-110.

Reynolds, D. (2003). Mindful parenting: a group approach to enhancing reflective capacity in parents and infants. Journal of Child Psychotherapy, 29(3), 357-374.

Rhode, M. (2004). Infant observation as research: cross-disciplinary links. Journal of Social Work Practice, 18(3), 283-298.

Ricci, L A. \& Hodapp, R. M. (2003). Fathers of children with Down syndrome versus other types of intellectual disability: perceptions, stress and involvement. Journal of Intellectual Disability Research, 47(4/5), 273-284.

Rodrigue, J. R., Morgan, S. B. \& Geffken, G. (1990). Families of autistic children: psychological functioning of mothers. Journal of Clinical Child Psychology, 19(4), 371-379.

Rosa, J. C. (1995). Reflexôes sobre o método da observação da relação mãe-bebê. Revista Brasileira de Psicanálise, 29(2), 299-305.

Rustin, M. (1989). Observing infants: reflections on methods. In: Miller, L., Rustin, M. E., Rustin, M. J. \& Shuttleworth, J. (eds.). Closely Observed Infants (pp. 52-75). London: Duckworth.

Rustin, M. (1997). What do we see in the nursery? Infant observation as "laboratory work". Infant Observation: The International Journal of Infant Observation and its Applications, 1(1), 93-110.

Rustin, M. (2003). Learning about emotions: the Tavistock approach. European Journal of Psychotherapy Counseling \& Health, 6(3), 187-208.

Rustin, M. (2006). Infant observation research: what have we learned so far? Infant Observation, 9(1), 35-52. 
Schmidt, A. P. (1996). Ainda sobre a questão da sexualidade do deficiente mental. Escritos da Criança, 4, 70-75.

Shuttleworth, J. (1995). A relação entre os métodos e modelos da Psicanálise e os da Psicologia do Desenvolvimento. Revista Brasileira de Psicanálise, 29(2), 219-234.

Skotko, B. (2005). Mothers of children with Down syndrome reflect on their postnatal support. Pediatrics, 115(1), 64-77.

Smith, T. B., Innocenti, M. S., Boyce, G. C. \& Smith, C. S. (1993). Depressive symptomatology and interaction behaviors of mothers having a child with disabilities. Psychological Reports, 73, 1184-1186.

Souza, M. S. I. (1995). Supervisão da observação da relação mãe-bebê. Revista Brasileira de Psicanálise, 29(2), 293-298.

Stores, R., Stores, G., Fellows, B. \& Buckley, S. (1998). Daytime behavior problems and maternal stress in children with Down's syndrome, their siblings, and non-intellectually disabled and other intellectually disabled peers. Journal of Intellectual Disability Research, 42(3), 228-237.

Talberg, G. (1995). A supervisão da observação da relação mãe-bebê. Revista Brasileira de Psicanálise, 29(2), 307-314.

Tanaka, C. \& Niwa, Y. (1991). The adaptation process of mothers to the birth of children with Down syndrome and its psychotherapeutic assistance: a retrospective approach. Infant Mental Health Journal, 12(1), 41-54.

Tanaka, C. \& Niwa, Y. (1994). A Psychotherapeutic technique for mother-child intervention: a case study of a Japanese Down syndrome child. Infant Mental Health Journal, 15(3), 244-261.

Trowell, J. \& Miles, G. (1991). The contribution of observation training to professional development in social work. Journal of Social Work Practice, 18(1), 49-60.

Trowel, J. \& Rustin, M. (1991). Developing the internal observer in professionals in training. Infant Mental Health Journal, 12, 233-245.

Tuters, E. (1988). The relevance of infant observation to clinical training and practice: an interpretation. Infant Mental Health Journal, 9(1), 93-104.

Watillon, A. (1997). A técnica das terapias conjuntas. In: Lacroix, M. B. \& Monmayrant, M. (eds.). Os laços do encantamento: a observação de bebês, segundo Esther Bick, e suas aplicaçôes (pp. 175-178). Porto Alegre: Artes Médicas.

Winnicott, D. W. (1971/1975). O brincar e a realidade. Rio de Janeiro: Imago.

Wirth, A. F. (2000). Aplicação do método de observação de bebês em uma UTI neonatal. In: Caron, N. A. (ed.). A relação pais-bebê: da observação à clínica (pp. 207-231). São Paulo: Casa do Psicólogo. 
Youell, B. (2002). The relevance of infant and young-child observation in multidisciplinary assessments for the family courts. In: Briggs, A. \& Meltzer, D. (eds.). Surviving space: papers on infant observation (pp. 117-134). London: Karnac Books.

\section{Notas}

${ }^{1}$ O projeto desta pesquisa foi aprovado e autorizado pelo Comitê de Ética em Pesquisa da Pró-Reitoria de Pesquisa da Universidade Federal do Rio Grande do Sul - UFRGS (Parecer $\mathrm{n}^{\circ}$ 2005470).

2 Todos os nomes dos personagens envolvidos na apresentação do caso são fictícios.

Recebido em 23 de julho de 2009 Aceito para publicação em 25 de abril de 2010 